\title{
A COSMOGONIA DE CHARLES FOURIER: A RECONSTRUÇÃO DO MUNDO EM UTOPIA E FICÇÃO CIENTÍFICA
}

\author{
Ivone Gallo
}

Quando nos nossos encontros no Centro de Pesquisa sobre Utopia (U-Topos-Iel-Unicamp) nos propusemos a uma reflexão ao redor do tema da ficção científica, imaginei, de início, o desafio desta empreitada para o historiador, acostumado, por exigência do ofício, ao apego ao empírico, a um suposto racional real legando a um segundo plano os domínios da imaginação. Então, desde logo, a opção temática abriu diante de mim a perspectiva do próprio questionamento sobre como construir novos objetos passíveis de uma escrita da história. Depois de muito divagar, lembrei-me da vontade antiga de analisar um texto do socialista francês Charles Fourier (1772- 1837), intitulado "Cosmogonie" (FOURIER, 1845, tomo I), ${ }^{1}$ que permaneceu secreto por algum tempo, pois os discípulos da École Sociétaire, centro em Paris que congregava fourieristas, temiam

1 Entre os anos de 1845 e 1858 , o jornal de propaganda fourierista La Phalange publicou os manuscritos de Fourier. Entre os anos de 1966 e 1968 a editora Anthropos, Paris, publicou, sob a direção de Simone Debout, a coleção das obras completas de Charles Fourier, em que se procurava seguir de maneira mais fiel os manuscritos. Nesta coleção, no tomo 12 encontramos os artigos Cosmogonie, Analogie et Cosmogonie, De l'Analogie, textos que haviam sido publicados pelo La Phalange de 1845 à 1849. Aspectos da cosmogonia de Fourier, entretanto, podem ser encontrados no conjunto de sua obra, como em Théorie des quatre mouvements (1808); tomo I das obras completas, Théorie de l'unité universelle 
uma repercussão ruim das ideias professadas ali pelo autor. Na verdade, os discípulos retomaram de diferentes maneiras o tema da cosmogonia. Victor Hannequin em Sauvons le genre humain! (1853) e em Religion (1854) se ocupou do papel de continuador da obra do mestre, acreditando conferir à cosmogonia uma maior consistência. Evidentemente, imprimiu ao assunto uma visão própria, apelando para o horror na tentativa de provocar uma reação na sociedade e uma mudança de conduta. Na sua versão, que preserva muitos dos aspectos da cosmogonia de Fourier, a Terra se reporta aos homens por meio de Hannequin (revelação) e de forma ameaçadora anuncia o fim do mundo em 1953, caso não haja intervenção. Já no caso de Mme Vve Dalibert, swedenborguista e fourierista, que escreveu La Nouvelle Jérusalém et le phalanstère ou De l'Union définitive de la religion et de la science (1839), transferiu no seu livro o foco central da análise para a doutrina de Swedenborg provocando com isto uma mudança substancial do eixo central proposto por Fourier, apesar de tocar nos temas da alma, das analogias e de Deus comuns ao mestre.

Como parece claro, foram muitas as inquietações iniciais até que pudesse montar a minha proposta de discutir a relação utopia/ficção científica dentro da perspectiva do socialismo da primeira metade do século XIX, mais especificamente em Charles Fourier e no movimento social do período, tema que como historiadora faz parte do meu universo de pesquisa.

É sempre muito difícil a abordagem de Charles Fourier, sobretudo no Brasil, onde é pouco conhecido e ademais compreendido sobretudo a partir da análise marxista, através da qual passou a figurar nos meios acadêmicos e militantes como socialista utópico, e não pelos seus próprios escritos e trajetória. A complexidade aumenta quando nos aventuramos a tratar, como vou fazer, de textos menos difundidos do autor e incontestavelmente mais polêmicos, pois sempre esperamos de um filósofo, cientista político, um discurso acabado, coerente e lógico sobre a economia, a política e a sociedade. O "Cosmogonie" (FOURIER, 1845, tomo I) não estaria isento evidentemente, de uma lógica interna, porém ousa em propor novos paradigmas para a reflexão científica e mais ainda para a existência em sociedade, de tal forma a exigir que, enquanto leitores, escavemos o texto em busca de seus sentidos. Eu passo então a

(1822-1823), tomo 2 à 5 das obras completas, Le Nouveau Monde Industriel et Sociétaire (1829), tomo 6 das obras completas, Le Nouveau Monde Amoureux, tomo 7, La Fausse Industrie (1835-1836), tomos 8 e 9. 
uma breve exposição sobre o "Cosmogonie" e depois interpreto buscando os elos entre utopia e ficção científica.

O texto se nos descortina a partir de uma bela ironia bem característica do autor:

\begin{abstract}
"Nós estamos na era da Cosmogonia, ciência que parece em voga, sobretudo na França, onde as ciências como os paramentos são objetos de moda. A Cosmogonia toma aí favor. Frequentemente, recolocamos em cena as doenças dos astros e o capítulo dos cometas, tão fragilmente tratados em 1811. Todo fazedor de sistemas se crê obrigado em consciência a fornecer uma cosmogonia, como em 1788 uma constituição. Nosso século é acusado de ter sozinho mais cosmogonias do que todos os outros juntos. Se poderia dizer o mesmo dos tratados de economia política. Infelizmente, em um e em outro gênero, quanto mais a ciência é fecunda em sistemas, mais ela é estéril em benefícios." (FOURIER, 1845, tomo I, p.339)
\end{abstract}

Nesta passagem Fourier reclama da estreiteza de compreensão dos intelectuais e cientistas, incapazes para uma visão integral do mundo. Pois a todos deveria parecer óbvio o fato de os humanos serem, na verdade, cosocietários de Deus na direção dos astros e, por isto mesmo, dotados de poder de influência sobre estas enormes criaturas (FOURIER, 1845, tomo I, p. 341). Os planetas, por sua vez tem vida, como nós, possuem também 12 paixões radicais e, a mais do que nós, 12 aromas radicais análogos às 12 paixões. Eles se comunicam e se relacionam através destes aromas. Seguro ainda sobre o sólido apoio de suas afirmações Fourier insiste: "Eu disse que um planeta é um corpo andrógino, provido de dois sexos e funcionando em masculino para as copulações do pólo norte e em feminino para aquelas do polo sul" (FOURIER, 1845, tomo I, p. 350) sendo ainda a sua procriação permanente e numa combinação sem número, quando os germes dos astros são depositados na via láctea "de onde saem num enxame de cometas que viajam por muito tempo e gravitam de ordinário sobre diversos sóis antes de se fixarem em plano em um turbilhão" (FOURIER, 1845, p.349) Para Fourier não existe apenas o universo, mas como em Fontenelle (1993), uma pluralidade de mundos (biniversos, triniversos, poliversos). Porém, em meio à multiplicidade e diversidade do mundo conhecido e desconhecido certamente há, para Fourier, um elo ligando todas as coisas entre si de tal forma que um movimento qualquer afeta o funcionamento do todo. Portanto, se na Terra, vivemos em desarmonia, isto impede o pleno desenvolvimento dos aromas dos outros planetas e, ao mesmo tempo, bloqueia os benefícios enviados à Terra pelos outros planetas. Os males experimentados na vida em sociedade não devem, entretanto, ser encarados como definitivos e tudo podevir a mudar sea humanidade passar 
a agir de acordo com os princípios da unidade universal, o que implicará no ingresso em uma fase de harmonia em todos os níveis de vida. Aí, o mundo físico se regenera ou se transforma. O primeiro sinal indicativo deste processo é o nascimento da coroa boreal a neutralizar de imediato os efeitos nefastos do inverno glacial em Petersburgo duplicando as colheitas (FOURIER, 1967, p. 99), as águas do mar também se beneficiarão dos efeitos da coroa boreal que "dentre outros benefícios, modificará o sabor dos mares, e decomporá ou precipitará as partículas betuminosas; por expansão de um acido cítrico boreal. Este fluido combinado com o sal, dará à água do mar o gosto de um tipo de limonada que nós chamamos de aigresel (aigre de cèdre). As transformações na água, que se torna mais doce, provocarão o expurgo de todas as horríveis criaturas marinhas substituindo-as por peixes e anfíbios a nosso serviço. Do mesmo modo que os monstros marinhos desaparecem, os vícios odiosos dos civilizados, bárbaros e selvagens também levam um golpe de morte e cedem lugar às virtudes, ao triunfo e às riquezas. (FOURIER, 1967, p 100, nota 1). Outras espécies nocivas e perigosas se extinguirão e darão lugar a seus opostos como os antitigres e os antileões com tendências colaborativas para com os homens. Um tigre, por exemplo, poderá carregar até sete viajantes de uma vez a uma velocidade de 20 a 25 milhas/h, correndo suavemente, quase tocando o chão. Antibaleias e antihipopótamos, auxiliarão na navegação rebocando e guiando as embarcações. Até os homens terão ampliados os seus sentidos: a sua visão será tão apurada quanto a da águia. A terra se regenerará e doará mais riquezas em ouro e prata em profusão, agora não mais escondidas nas profundezas, mas acessíveis na superfície do planeta. Mas o estabelecimento de uma nova ordem social provoca também mudanças para as almas dos mortos. Sobre isto vejamos:

"As almas dos defuntos gozam de diversos prazeres que nos são desconhecidos, entre outros o prazer de existir e de se mover. Não se tem conhecimento deste bem estar, comparável àquele da águia que plana sem agitar as asas. Tal é, no outro mundo, o estado dos defuntos ou transmundanos; providos de um corpo aromal, bem mais leve que o ar, eles planam no ar, e além do mais através da espessura da terra, assim eles podem atravessar as rochas as mais compactas sem obstáculo" (REYBAUD, 1852, p. 269-270)

Para Fourier, o efeito disto é provado pela agulha imantada que o fluido magnético dirige ao seio das rochas as mais espessas. (REYBAUD, 1852, p. 169) E assegura que se suas visões parecem fábulas para os físicos e químicos, na verdade, há um engano dos cientistas quanto aos meios empregados para se conhecer a natureza. A natureza não está coberta por um véu como pretendia Anacharsis. Com o recurso da analogia, 
da associação, o homem pode adquirir uma pré-ciência do futuro e do passado. Na ordem civilizada "a maior parte dos assalariados [escravos] se dariam a morte se eles pudessem contar com segurança sobre uma vida futura na qual eles veriam uma chance de escapar à sua terrível miséria" (FOURIER, 1967, p. 127) A alma que deixa o corpo desfruta de vidas na terra e em outros planetas assumindo um corpo de outro tipo, aromal, etéreo, incombustível e homogêneo ao fogo, porque não pode haver separação entre matéria e espírito, portanto a vida celeste é também material e as almas sentem e trabalham por nós. Com base em cálculos matemáticos é possível estabelecer uma escala geral das metempsicoses de almas durante os 27.000 anos de harmonia previstos para a humanidade e entre este mundo e os outros uma alma poderá se deslocar 405, 810 ou 1620 vezes.

Em suma, a base das concepções de Fourier se encontra em franca oposição aos demais sistemas de explicação do universo, geralmente fundados na ordem do mundo para justificar o estado social em que vivemos (NATHAN, 1981, p. 83). O caso da popularização das descobertas de Herschel sobre o mundo habitado da Lua a reproduzir a opressão entre seres diferentes, como acontece entre nós na Terra, é revelador do complô entre a ciência e a religião, como Fourier se esforça por fazer nos compreender, na tentativa de se manter a humanidade cativa. A observação dos astros apenas adquire um sentido pelo conhecimento que poderíamos ter da condução da vida em outros planetas que certamente transcorre muito melhor neles do que na Terra. Os planetas não são o espelho da Terra, mas devem se converter, ao contrário, no modelo a ser imitado, de harmonia e felicidade (NATHAN, 1981, p. 77-79). Pois, existe uma unidade (Deus) que promove uma ligação entre todas as coisas, de tal forma que, se atingimos o conhecimento sobre um fragmento da realidade portas são abertas para o conhecimento de outros que lhe são análogos. A dificuldade reside em decifrar o código das analogias estabelecendo o que é análogo a que.

Movido pelo interesse em atingir o desconhecido, Fourier relaciona uma teoria social ao método de Newton e associa as catástrofes climáticas e cósmicas ao horror provocado pela Civilização. Porque não conseguimos ultrapassar o estado atual de civilização, protelamos a experimentação de um estado de felicidade geral, que aliás nos é predestinado, prejudicando também o desenvolvimento dos outros planetas que poderiam estar agindo de maneira mais adequada para o surgimento de novas criações na terra e no espaço. A solução para este impasse é advogarmos uma nova ciência, a da Associação, que permitiria a superação do regime industrial atual, um verdadeiro desastre, para o regime industrial societário que produz riquezas, felicidade e harmonia. A Associação de que nos fala Fourier 
representa uma adaptação da lei da atração de Newton ao contexto social e produtivo. Através da concepção da atração passional parecia possível associar em um espaço comunal pessoas de ambos os sexos, de diferentes idades, gostos e inclinações para uma vida comum e trabalho atraente.

As concepções de Fourier, sem dúvida, levantam temas polêmicos para o debate ao redor da utopia e da ficção científica, algo que a princípio me desencorajou, porém, depois de muita reflexão, concluí ser este diálogo possível. A parte referida sobre a polêmica reduzo a duas questões principais: uma concepção reducionista tanto das ciências, quanto das utopias e que haviam sido impostas em nome de um socialismo científico, algo que persiste e que é preciso ultrapassar. Sobre isto abro um parêntesis necessário para dizer que aceito, por enquanto o uso do termo utopia para a análise do socialismo do século XIX, embora reconheça que existe uma discussão sobre se o termo utopia (na verdade, título da obra de Morus) caberia para caracterizar, identificar coisas distintas da obra do humanista. Isto é, características específicas da obra de Morus como, por exemplo, construção em narrativa, e não intuito de fornecer para o leitor um plano de ação para a transformação social e ainda a referência apenas implícita a tempos e lugares não claramente definidos. Tudo isto, em princípio, desautorizaria a classificar escritos de outra natureza (tratados filosóficos, escritos de análise política, etc.) como utopia. Então fica a dúvida sobre se o mais correto seria falarmos em Utopia (restritivo) ou eunomia (boa lei, que abre espaço para pensarmos também as anti-utopias e distopias). A minha aceitação se explica pelo fato de Fourier recusar, ao modo do século XIX, a alcunha de utópico (sonhador) e de Marx imputar ao socialismo anterior ao materialismo o nome socialismo utópico, no sentido de não científico. A aceitação do termo utopia, conceito atualmente positivado, me permite tratar destas coisas, até porque sobrevivem em Fourier aspectos encontrados na literatura utópica do século XVI e XVII e XVIII o texto que analisamos aqui dispensa outros exemplos-, apontando para o fato de um possível conhecimento por ele do gênero e de sua incorporação em seus escritos e até de alguns de seus discípulos.

Ao lermos o Cosmogonie de Fourier somos levados a identificar nele algumas características apontadas por David Ketherer no "The Apocalyptic Imagination, Science Ficction, and American Literature” (ROSE, 1976). A primeira delas seria o fato do texto apresentar uma resposta às mudanças súbitas nas condições sociais, algo sempre mencionado por Fourier em diferentes obras. Outro traço forte para uma comparação entre utopia e ficção científica encontrado em Fourier é a tentativa de manter um elo com o real pelo efeito da analogia e da verossimilhança, porém extrapolando o real conhecido a ponto de nos fazer enxergar o real possível, ou ainda 
não conhecido, mas tangível. E daqui surgem dois novos elementos para uma aproximação: o emprego de um tom profético na escrita (o destino de felicidade nos espera) e, por fim, o desejo de praticar a utopia, isto é, o que estava antes na forma texto, na imaginação. Este último ponto é bem evidente em Fourier e em seus discípulos, tendo sido muitas as tentativas de estabelecimento de comunidades fourieristas em diferentes continentes ao longo do século XIX. Mas, ocorre também em Cabet, comunista, que no seu Voyage en Icarie delineou uma sociedade ideal, posta em execução mais tarde na América do Norte.

A aproximação entre utopia e ficção científica pode ser viável a partir da constatação de que ambas são como capacidades humanas de pensamento e criação a partir da experiência, porém da experiência pensada fora do quadro dos saberes institucionalizados, ou convencionalmente aceitos, daí a necessidade da ficção científica como suporte nas formulações utópicas desde Bacon até Fourier. Inversamente, a utopia como busca e como investigação sobre o implícito, o invisível, o possível revela uma ambição científica fundadora de novos modelos de explicação do mundo, o que por sua vez nos remete à idéia de que na ficção científica possa existir mais de ciência do que se imagina. Aqui então entramos na segunda questão, e a mais difícil, que trata justamente de encontrar algum parâmetro para ancorar uma concepção de ficção científica capaz de dar conta do que prometemos neste texto.

Ao longo das investigações preliminares que fizemos nos pareceu evidente a dificuldade geral dos estudiosos analisados em encontrar definições muito estritas de ficção científica e alegações sobre a incapacidade de se chegar a uma caracterização definitiva do gênero. Um caminho possível encontrei num artigo de Sergio Lehman intitulado "La Légende du processeur d'histoire" (2006) em que o autor admite, de fato, uma impossibilidade de definição da ficção científica, mas apenas se para isto partirmos de temas ou conteúdos que lhe sejam próprios. Além disto, uma definição não poderia excluir os sujeitos (autor/leitor) nem a ambivalência entre real/não real, metafórico/literal, o sense of Wonder, o encantamento, a vertigem. Tudo isto define a ficção científica como uma experiência estética. Esta experiência estética acontece quando somos transportados através das imagens numa viagem vertiginosa para o outro lado do espelho. Há um estranhamento, porque há uma inversão de posição que leva o sujeito a entender o real como ficção e a realidade do mundo seria sua contra parte (o outro lado do espelho). Então, a ciência, a tecnologia, a perscrutação do futuro são, na verdade, instrumentos que provocam o sentido, o meio de acesso ao verdadeiro. Isto é muito impressionante porque Lehman (2006) opera uma autocrítica afirmando 
que não se chega a uma definição da ficção científica racionalmente, o que a define está na própria vertigem e encantamento e, ao mesmo tempo, o forte vínculo com a experiência do cotidiano.

Os pressupostos de Lehman nos levam claramenteà percepção de que esse sense of Wonder está nos contos de ficção científica como fora deles. A visão de que algo extrapola é compartilhada também pelo antropólogo Louis-Vencent Thomas para quem a ficção científica nas suas funções críticas e descritivas "bem poderia ser a sociologia imaginária de nosso presente" (LEBAS, e COUSSIEU, 2011, p. 6). Fréderic Lebas e Wilfried Coussieu (2011) acrescentam que para pensar a ficção científica é preciso, em primeiro lugar, se interessar pela postura do autor: "Com efeito, nos futuros que se dão a ler e a ver através dos contos, uma das qualidades que compõem a narração, o escritor, é aquela de estar investido de um senso agudo do presente" (LEBAS e COUSSIEU, 2011, p. 4). E, na gama de escritores estariam incluídos os filósofos, ensaístas e poetas, aqueles dotados de clarividência e imbuídos de um sentido de construir o mundo, recriá-lo ou até mesmo destruí-lo. Mas para Lehman (2006), além disto, é preciso ir ao leitor, ao público, sem o qual a vertigem não se realiza (temos que ter do outro lado a parte disposta a embarcar para a viagem e que constitui o próprio motivo do autor e do texto. Há comunidade na construção do texto.)

Os problemas levantados por estes autores inspiraram as minhas investigações. Charles Fourier, consideradoum socialistautópico, preenche alguns dos requisitos dos quais tratamos, sobretudo pela capacidade crítica e analítica sobre o seu próprio tempo eainda por responder às necessidades do operariado, dos escravos, das mulheres e das crianças do seu tempo. A biografia de Fourier revela que os acontecimentos trágicos vivenciados por ele contribuíram decisivamente para que tivesse optado por um deslocamento diante do seu próprio tempo. Isto o tornava um personagem enigmático, criticado e ironizado, a ponto de ser tratado como louco, algo denunciado até mesmo pelas três primeiras letras de seu nome FOU, como apontavam seus detratores. Por ter passado a juventude em meio ao processo revolucionário de 1789 , então vivendo na atmosfera de terror, fome e disputas pelo poder, Fourier adquiriu a visão de que tudo aquilo bem poderia ser evitado se a humanidade superasse o estado de Civilização. Para ele, em civilização, o homem conquistou um desenvolvimento em tecnologia, mas não soube criar os meios para fazer das descobertas um benefício geral, para todos. A partir desta constatação e munido da visão de como chegar lá, Fourier debruçou-se sobre o problema nos legando várias obras. Resumidamente, defende um tipo de socialismo, inserido no quadro do pensamento e do movimento social da primeira metade do 
século XIX, desenvolvido a partir de comunidades agregando um número específico de pessoas diferentes em personalidades, inclinações, talento e capital. Socialmente, a parte mais difundida de sua obra foi justamente esta, explicada com base na matemática, no cálculo e aparentemente mais aceitável pelo caráter científico que se procurou conferir a ela. Aqui estamos tratando da parte menos difundida, a Cosmogonia, e vista como extremamente problemática por fourieristas da École Sociétaire, cujo objetivo seria a propaganda apenas da teoria societária. Entretanto, comprovou ser a parte de maior interesse para o movimento operário da época e para a dissidência fourierista. Alguns autores fazem referência à predileção pelo operariado de literatura utópica (PARIS, 2002; RUDE, 1980); por outro lado, o próprio material de popularização da teoria saído da École Sociétaire apresentava-se fartamente recheado de publicações, como os Almanach Phalanstèriens contendo mensagens escatológicas e imagens de futuros perfeitos substituindo o caos do presente. Publicações científicas, pseudo científicas de época e dos próprios dissidentes abordam ciências, cosmogonias, astronomia, magnetismo de tal forma que estas produções nos autorizam a afirmar que entre o século XVII e o século XIX existe uma zona de ambiguidade entre a ciência e a imaginação a impedir que se aceite ser a ciência fruto do exercício de uma objetividade fundada exclusivamente no racional (DARNTON, 1987). Eu penso que o termo ficção científica nasce inclusive como ironia e crítica a uma tal compreensão de ciência depurada da sua cota de licença. Os franceses que reivindicaram para si a primeira tentativa de denominação do gênero, antes dos americanos, chamavam-no de merveilleux scientifique, termo, inclusive pleno de conotações culturais (o merveilleux é um estado ou um lugar, uma magia ou uma revelação, etc) e que de uma maneira muito clara define mais aquilo que a ciência porta de ficção do que o contrário. Isto é, a ciência, tal como a compreendemos simplesmente não pode existir sem a imaginação, a inquietação e o desejo de ir além do visível e do conhecido que a antecede.

A presença portanto, no socialismo do século XIX, da idéia de uma pluralidade do mundo e da reencarnação da alma em outros astros, não nos aparece mais como esdrúxula. Essas coisas se converteram também em tema recorrente em Dumas, Eugéne Sue e Henri Martin, ou, além disto, é constitutivo da revelação primitiva, no swedemborguismo, druidismo, espiritismo, magia e no ocultismo (NATHAN, 1981). Algo entretanto difere esse gênero de cosmogonias daquelas dos socialistas. Se por um lado no tema religioso parte-se do princípio de que o homem seja um pecador e que o usufruto de nova vida em outros mundos venha como um prêmio por sua regeneração, para os fourieristas a perspectiva 
do pecado seria inconcebível. Tudo isto acaba se entrelaçando a objetivos sociais de construção dos mundos apoiadas em linguagens científicas e religiosas ou na mistura de ambas. Seria muito difícil aqui reconstruirmos os caminhos que levaram a estas sínteses, pois isto exigiria estudos mais abrangentes, todavia, podemos destacar alguns elementos significativos para compreendermos a crítica à ciência no século XIX e o surgimento de uma nova ciência construtora de uma nova realidade de harmonia social, uma utopia.

Um grande paradigma para pensarmos o século XIX é a Revolução Francesa do final do século XVIII cujos impactos fizeram-se sentir no mundo todo. No tempo em que ocorreu inclusive, foi sentida como um abalo cataclismático. Até aquele momento a palavra revolução servia apenas para designar movimentos astronômicos e sem revelar rupturas com uma ordem celeste predeterminada. Isto traduzido para o terreno social significava um movimento dentro da ordem, isto é, sem implicação de mudanças estruturais, algo que a revolução de início parecia negar com a crítica iluminista às monarquias e ao status aristocrático. Então percebemos que já no enfoque iluminista ainda parecia vigente uma interpretação dos fenômenos sociais a partir dos fenômenos naturais. Assim, por exemplo Starobisnky (1988), na sua conhecida interpretação dos antecedentes da revolução a partir das manifestações artísticas, já prenunciava não apenas os sinais do cataclismo, inscritos na fome do ano anterior à revolução, como a imagem resplandecente da revolução no mito solar que iluminava o mundo, irradiado a todos os lugares.

Acredito que uma interpretação desta natureza para um fenômeno social só pode ser possível por uma mudança fundamental na compreensão dos fenômenos do mundo físico ocorrida já no século XVII com as descobertas de Newton, que inclusive serviram de calço para as argumentações do próprio Fourier. Nos Principia de 1686, Newton formalizaria definitivamente a teoria da atração universal a partir da existência de uma força centrípeda exercida por dois corpos um sobre o outro. Essa força centrípeda, ou força da atração, seria proporcional às respectivas massas dos corpos, e inversamente proporcional ao quadrado da distância que os separa. O assunto apesar de complexo ganhava popularidade e nos perguntamos a que isto se deve? Sem dúvida, inicialmente, ao modo como Newton abordava a teoria da gravidade, a simplicidade da sua exposição e ao fato de dar conta de diferentes fenômenos em escala local e aparência, como, por exemplo, a queda de objetos ao chão, as marés, o achatamento da terra em seus pólos, o movimento dos planetas e seus satélites (MERCKLE, 2001). Mas, não podemos nos esquecer de um interesse popular natural pelos fenômenos 
físicos, incontroláveis, e muito associado aliás, à religião e que na Europa, desde a idade média assumia proporções assustadoras com a eminência de um apocalipse como vingança divina contra os pecadores. Mas sob Newton, sem dúvida, houve uma mudança fundamental nos padrões metodológicos e na própria concepção de ciência a partir da idéia de que apenas devemos admitir causas que sejam necessárias na explicação dos fenômenos, isto é, nem a metafísica, nem a teologia servem para explicar o sistema do mundo. Imaginamos o quanto isto deva ter se convertido em matéria de interesse do mundo acadêmico e também do público em geral.

A retomada de Newton no final do século XVIII e início do XIX trará novidades. No momento em que Fourier escreve, o modelo newtoniano representa a racionalidade física e matemática, portanto a rejeição do modelo metafísico e essencialista em proveito da indução e da experimentação. Para Fourier, que viveu a Revolução francesa como uma experiência devastadora, era preciso explicar racionalmente este processo na tentativa de fazer da história uma trajetória segura e previsível rumo a um mundo de harmonia e felicidade. Não seria mais ou menos isto a que Lehman se refere no seu artigo? Ora, a revolução, na fala dos iluministas prometia essas coisas, mas o período do terror já indicava uma falha no cálculo no modelo oferecido por eles como substituição do antigo regime. A partir desta constatação, isto é, do modo como a revolução aprofundou a pobreza, as tormentas econômicas e os desentendimentos políticos em escala local e continental, Fourier passou à recusa das respostas oferecidas pela filosofia desde a antiguidade clássica. Uma passagem célebre na terceira parte do Théorie des Quatre Mouvements (FOURIER, 1967) intitulada "Confirmation tirée de l'insuffisance des sciences incertaines, sur tous les problémes que presente le mécanisme civilisé” inicia com a seguinte afirmação:

\footnotetext{
"Aristóteles, um dos nossos sábios mais incensados, via com modéstia suas próprias luzes; sua devisa era Que sei eu? Isto é sem dúvida o que ele disse de melhor.Os modernos pouco se inclinam a uma tal modéstia, e entretanto são eles mais sábios que Aristóteles em política social? Não, porque não vemos nós sempre, como na antiguidade, apenas a indigência, a malandragem e as revoluções: e de acordo com as tempestades que nossas luzes modernas suscitaram sobre a geração presente, não houve jamais um século em que os sábios merecessem melhor a devisa Que sei eu? (FOURIER, 1967, p. 181)
}

Por ciências incertas Fourier entende a própria filosofia e os campos de que ela trata como a moral, a economia e a política. Os filósofos são tratados de malabaristas, fazedores de sistemas que infalivelmente erram por estarem descolados da experiência, por serem obras fantásticas de 
mentes solitárias. Vê neste gênero de cientista um oportunismo, como foi comprovado pela revolução em que os iluministas ascenderam ao poder para reproduzir os mesmos vícios daqueles que criticavam (aristocracia e igreja). Os problemas propostos pelos filósofos são falsos e as soluções que apresentam são perigosas ou inúteis. Mas Newton, por exemplo, também não oferece respostas para perguntas como "Porque a Terra possui luas e Venus não? Por que Saturno possui um anel luminoso e Jupiter não?” (FOURIER, 1967, p. 85) Para Fourier é preciso ir à metafísica para responder a certas questões. A solução apresentada por Newton é igualmente inútil, afinal, para que nos serve saber o peso de cada planeta? Em suma, a falha do físico está em se perguntar sobre os efeitos, deixando de lado as causas e, por outro lado, ocupar-se do mundo material sem inquirir-se sobre o mundo espiritual e social. Se assim é, qualquer mudança só pode ser pensada fora dos parâmetros do conhecimento estabelecido pela busca de uma Ciência Social da qual Fourier pretendia tentar a descoberta. Uma refundação do saber, necessário e útil dependerá de duas coisas fundamentais que Fourier porá em prática: a dúvida absoluta e o total afastamento. Descartes já havia posto a questão da dúvida como algo importante, mas não fez bom uso dela. Fazia perguntas ridículas como duvidar da sua própria existência enquanto é preciso se questionar sobre coisas mais importantes e até de assentimento universal como é o caso do elogio à Civilização, tão alardeado pelos iluministas. É preciso aplicar a Dúvida à Civilização, "duvidar de sua necessidade, de sua excelência e de sua permanência” (FOURIER, 1846, p.4) Porém, os filósofos não saberiam fazer isto sem por em risco suas próprias teorias. Aqui é importante ressaltar que Fourier se coloca na posição de um inventor, desligado de qualquer partido e que por isto pode adotar uma dúvida absoluta.

O écart absolu representa um conceito central para Fourier e define o distanciamento que devemos preservar, em todos os sentidos, das rotas seguidas pelas ciências incertas, pois não se perguntam sobre coisas úteis e não respondem às necessidades do corpo social, são utópicas. Então ao invés de tratar de sacerdócio, tronos e governos Fourier vai se ocupar de assuntos não tratados pelos filósofos. Ao invés de tratar de indústria, tratará da associação, ao invés de falar em controle das paixões (moral) descobrirá que a felicidade depende da liberação das paixões, ao invés de fazer o elogio à civilização buscará pelos destinos da humanidade. Assim explica suas descobertas:

"Eu logo reconheci que as leis da atração passional estavam em todos os pontos conformes àquelas da atração material, explicadas por Newton e Leibnitz, e 
que havia UNIDADE DO SISTEMA DE MOVIMENTO PARA O MUNDO MATERIAL E PARA O MUNDO ESPIRITUAL.

Eu suspeitava que esta analogia podia se estender das leis gerais às leis particulares, que as atrações e propriedades dos animais, vegetais e minerais estavam talvez coordenadas ao mesmo plano que aquelas do homem e dos astros...Assim foi descoberta uma nova ciência fixa: A Analogia dos quatro movimentos material, orgânico, animal e social, ou Analogia das modificações da matéria com a teoria matemática das paixões do homem e dos animais. (FOURIER, 1846, p.12)

Por este método ele penetrou os mistérios da natureza que os filósofos afirmavam impenetráveis e descobriu um novo mundo científico capaz de fornecer a chave para um cálculo dos destinos universais e das leis de todos os movimentos presentes, passados e futuros, uma similitude entre o homem e o universo, uma relação entre extremos, entre razão e emoção, matéria e espírito, homem e deus. A descoberta de que uma força de atração torna o homem, a natureza e Deus coisas relacionadas, o fez chegar a uma teoria da unidade universal (verdadeira ciência) cujo princípio ativo é Deus (espírito/matéria/justiça matemática)

Essas descobertas tornaram-se possíveis a partir da analogia, porém a analogia propõe mais do que um jogo comparativo de similitudes entre homem e natureza. O homem é certamente o centro, pivot, da criação, cada astro reflete o estado social da humanidade de tal forma que a existência de bichos peçonhentos se explica pela "necessidade de um sistema de analogia com os vícios como a ferocidade e a calúnia” tão comuns entre os humanos (FOURIER, 1966-1968, t. XII, p. 210). A montagem de um sistema de analogias aparentemente apoiou-se no modelo de classificação serial dos seres vivos utilizado pelos naturalistas que compreendiam o todo como um organismo cujas partes se relacionam (indivíduo-todo) ou como um corpo em que cada órgão desempenha uma função útil e necessária e só pode existir relacionado à função. Mas, em Fourier, a finalidade e o uso dos conhecimentos em física e ciências naturais caminham numa direção oposta à do esperado. Eis que na nova apresentação a natureza converte-se num espelho que reproduz o estado de civilização, as próprias relações entre os homens e converte-se num verdadeiro hieróglifo a ser desvendado.

Um exemplo, seria a girafa como o hieróglifo da verdade: "Pois o próprio da verdade é superar o erro, é preciso que o animal que a representa eleve sua fronte acima de todos os outros, tal é a girafa..." (FOURIER, 1846, p. 287) A girafa é antes a materialização do destino da verdade em civilização. Como interpreta Arantes, na versão de Fourier: 
"a girafa e a verdade em civilização se tornam ridículas e excitam o riso, prova suplementar da incompatibilidade entre a verdade e a forma social que se recusa a se impregnar dela em toda sua extensão. A condição de existência da verdade em civilização é a de uma existência em separado, objeto de contemplação à parte das formas e dos conteúdos de sociabilidade. Ao isolar a verdade, a civilização a oprime. Assim, a inutilidade da girafa nos assinala a inutilidade da verdade em civilização e se pretendemos saber a que viria a verdade em outras formas sociais é preciso estudar o problema no hieróglifo da contragirafa, nas renas "animal do qual extraímos todos os serviços imagináveis." (ARANTES, 1992, p. 89)

A partir do exemplo sarcástico de Fourier, podemos compreender melhor a releitura que fez de Newton na nova fórmula les attractions sont proportionnelles aux destinées, o que vale dizer que cada ser desempenha um papel no concerto universal da Natureza e as suas capacidades devem ser adaptadas a um propósito. Se decifrarmos os códigos da natureza, através do emprego de uma ciência verdadeira alcançaremos a harmonia (a utopia se realiza), pois todas as possibilidades estão inscritas na natureza.

A utopia, por seu turno, "É o sonho do bem sem meio de execução, sem método eficaz” (FOURIER, 1966-1968, v. XI, II, p. 356). Aqui entra a ciência como ferramenta importante na realização da utopia. Mas qual ciência? Certamente não aquela que começa sua inquirição a partir da dúvida, mas uma outra que se pergunta sobre nossos desejos e se dirige apara a felicidade geral. Uma nova ciência deve reconhecer como princípio o fato do mundo físico desenhar-se como o mundo social e que o conhecimento das leis naturais nos leva a entender efeitos das leis sociais. A ciência não pode pretender reger com leis próprias o mundo físico (MERCKLÉ, 2001), mas, como sistema, deve agregar três elementos imprescindíveis: o saber, a paixão e a ação (ARANTES, 1992, caps. 2 e 3); deve também ir do conhecido ao desconhecido, habilidade facultada pela analogia, ir da análise para a síntese e responder a todas as perguntas. Isto posto, a ciência estaria apta a criar porque atrelada à experiência saberia descobrir um novo código social.

Para concluir façamos alguns nexos necessários. Primeiramente, entre utopia e ciência, para mim muito evidente no caso de Fourier em pelo menos dois pontos: 1- na medida em que uma intervenção sobre a realidade depende de um cálculo sensível ligando a matemática às paixões e 2- a partir desta constatação o reconhecimento de que é preciso refazer a tradição clássica aliando-a à tradição moderna para refazer a concepção de ciência e juntamente com ela a da sociedade. A ciência abandonaria a concepção de natureza como mistério indecifrável rompendo com a divisão sujeito/objeto, incorporando as tecnologias, mas admitindo o mergulho em aventuras desconhecidas, nas fantasias. $\mathrm{O}$ que nos parece em jogo para o problema 
da utopia e da sua vinculação com a ficção científica é uma concepção de ciência, pois em uma e em outra, a ciência é o instrumento que controla e fabrica um real hiper real ou surreal. No caso de Fourier, as matemáticas são vistas como a ciência das ciências, não pela possibilidade de cálculos fechados, mas pelos estudos gerais de proporções necessários para o cálculo das atrações que levam à harmonia social. Então, a razão, em si, não é o promotor da realidade. O desejo é, ao contrário, o verdadeiro motor e a razão o meio de fazer acontecer. A realidade portanto, não é racional é um jogo incerto de desejos que demandam uma organização, não um controle, pois está sempre em metamorfose, aberta aos desejos e, a ciência, por sua vez deve estar aberta aos imponderáveis. A tecnologia e a ciência têm sido fundamentais para o aumento da produção e este conhecimento herdado não deve ser desperdiçado, porém, se pretendemos mudar o mundo, não basta o desenvolvimento das forças produtivas, mas é preciso descobrir os nossos desejos e esperanças, nossas necessidades e mais, nossa verdadeira natureza cuja ordem social deve assemelhar-se. A cosmogonia de Fourier, quando toca no problema da imortalidade da alma, invoca, sem dúvida a nossa capacidade de transcendência e aperfeiçoamento progressivo, mas ao mesmo tempo, impõe os limites da realização da filosofia, pois a realidade é incapaz de realizar completamente os nossos sonhos que estão sempre à frente dela. Em contraposição ao anti humanismo contemporâneo, que vê no desenvolvimento tecnológico a perda de identidade, de personalidade num mundo industrial que fabrica comportamentos estereotipados, crítica muito presente na ficção científica, Fourier retoma a existência da alma, morada das paixões como a bússola da ciência verdadeira, aquela capaz de inventar um novo mundo.

\section{REFERÊNCIAS BIBLIOGRÁFICAS}

ARANTES, Urias. Charles Fourier ou l'art des passages, Paris: Editions Harmattan, 1992 (Col "La Philosophie em commun")

BLANQUI, Louis-Auguste. L'Eternité par les astres, hypothèse astronomique., Baillière, 1872

DARNTON, R. Boemia literária e revolução: o submundo das letras no Antigo regime, São Paulo: Companhia das Letras, 1987.

ESQUIROS, Alphonse. De la vie future au point de vue socialiste, Marseille, 1850.

FONTENELE. Diálogos sobre a pluralidade dos mundos. Campinas (SP): Editora da Unicamp,1993 (Col. Repertórios) 
FOURIER, Charles. "Cosmogonie" in La Phalange: revue de la science sociale, Paris: Imprimerie Lange Lévy et Compagnie, $1^{\circ}$ sem 1845.

. Théorie des quatre mouvements et des destinées générales, $3^{\mathbf{a}} \mathrm{Ed}$, Paris: Librairie Sociétaire, 1846

. Théorie des quatre mouvements et des destinées générales, Paris: Jean-Jacques Pauvert, éditeur, 1967.

. Oeuvres Complétes de Charles Fourier, 12 vols. Paris: Anthropos, 1966-1968.

LEHMAN, Serge. La legende du processeur d'histoir. Cycnos, vol 22, no 1 , posta on line 15 de novembro de 2006, pp 1-56 URL: HTTP://revel.unice.fr/cycnos/index.html?id=451

MERCKLÉ, Pierre. Le foisonnement analogique dans la "science sociale" de Charles Fourier In Cahiers Charles Fourier, Besançon: Association d'Études Fourieristes, no 12, 2001, pp 57-71.

NATHAN, Michel. Le ciel des fouriéristes: habitants des étoiles et réincarnations de l'âme, Lyon: Presses Universitaires de Lyon, 1981

PARIS, Robert. Utopia e Ciência no imaginário Socialista In História, São Paulo: editora da Unesp, v. 21, 2002, PP 13-39.

REYBAUD, Louis. Études sur les réformateurs ou socialistes modernes, Bruxelles: Vve Wouteus, 1852, vols 1 e 2 .

RIGNOL, Löic. Les hiérogliphes de la Nature. Science de l'homme et Science Sociale dans la pensée socialiste em France, 1830-1851. Tése de doutoramento Universidade Paris VIII, 2003

ROSE, Mark (org) Science Fiction: a collection of critical essays, Prentice-Hall:Englewood Cliffs, N.J., 1976

RUDE, Fernand (org e apresentação). "Allons en Icarie”. Deux ouvriers viennois aux ÉtatsUnis en 1855, Grenoble: Presses universitaires de Grenoble, 1980 (Col. L’Empreite du Temps)

LEBAS, Fréderic; COUSSIEU, Wilfried. Avant propôs. La Science-fiction, litérature ou sociologie de l'imaginaire? In Sociétés Revue des Sciences Humaines et Sociales, no 113, 2011/3 Editor: De Boeck Université, pp 5-13 HTTP://wwwcairn.info/revuesocietes-2011-3.htm

STAROBINSKY, Jean. 1789: os emblemas da razão, São Paulo: Companhia das Letras, 1988

SUVIN, Darko. La metamorfosi della fantasciencia. Poetica e storia di um genere litterario Bologna: Il Mulino, 1985 (Col. Le occasioni, 3)

TUZET, Heléne. Le cosmos et l'imagination, Paris: Librairie José Corti, 1965 . "Deux types de cosmogonies vitalistes: Charles Fourier, Victor Hennequin" Revue des Sciences Humaines, no 101, Janeiro-março 1961, pp 37-54. 